\title{
A Coordination Mechanism of Supply Chain with a Retailer and Two Competitive Suppliers
}

\author{
Zhi-yang Liu, Yong Liu (D), and Hui Li \\ School of Business, Jiangnan University, Wuxi 214122, China \\ Correspondence should be addressed to Yong Liu; clly1985528@163.com
}

Received 2 December 2019; Revised 3 May 2020; Accepted 12 May 2020; Published 31 May 2020

Academic Editor: Marcelo Messias

Copyright ( 92020 Zhi-yang Liu et al. This is an open access article distributed under the Creative Commons Attribution License, which permits unrestricted use, distribution, and reproduction in any medium, provided the original work is properly cited.

To deal with coordination problem of a supply chain consisting of two competitive suppliers and a dominant retailer, considering these factors such as cooperation effort degrees and competition on the supply chain members, we establish a two-stage model considering cooperation effort degrees and competition of the suppliers from the perspectives of decentralized decision and centralized decision and exploit it to discuss the optional decisions and explore the impact of cooperation effort degrees on the profits of supply chain members. Then, we use a group negotiation model to establish a coordination mechanism. The results reveal that the decision variables and overall profit of the supply chain of suppliers and retailers under centralized decisions are better than those under the decentralized decisions. Besides, the degree of competition and price sensitivity have positive and negative effects on the efforts of suppliers and retailers, respectively. Meanwhile, the degree of cooperation between suppliers and retailers affects the profits of supply chain members and the whole supply chain in different degrees. Finally, the proposed valueadded profit distribution mechanism can effectively deal with conflict problem and guarantee supply chain members and supply chain to maximize their profits and adopt the centralized decision.

\section{Introduction}

With the rapid development of science and technology and the deepening of economic globalization, strengthening supply chain management is much more important for enterprises to obtain profits and enhance their competitive strength in the increasingly fierce market competition. However, retailers and suppliers often make decisions according to the maximization of their profits in the process of supply chain management, and then there exists a variety of conflicts among supply chain and supply chain members, which influences the stability and sustainability of the supply chain. The beauty industry has been in a state of constant enthusiasm in the global market in recent years, and since China is a market with huge profit margins, many foreign brands are constantly pouring into the Chinese market. Under the competitive relationship between local brands and foreign brands, they will gradually adopt a cooperative strategy to enhance the competitiveness of their brands and occupy a certain market share. As a well-known retail brand based on health and beauty, Watsons is headquartered in Hong Kong, China, and sells a lot of beauty products every year. The main suppliers of products for Watsons are Mentholatum and Nivea; Mentholatum and Nivea both produce women's skin-care products and men's skin-care products. They provide the same type of products, mainly providing some beauty products and washing products to Watsons. In the health and beauty awards party held by Watsons in 2016, Mentholatum, which featured the young line, won the fashion beauty awards. The products provided by Mentholatum sold more in Watsons and brought higher profits to Watsons. Therefore, Watsons focuses on the longterm profits and chooses to cooperate with Mentholatum to produce products and sell co-branded products. On the one hand, Watsons's products are losing their competitiveness in the competition of many brands, so Watsons needs to cooperate with Mentholatum to form a cooperative alliance to improve the competitiveness of products, occupying a larger share in the market, and thus to obtain more profits; on the other hand, compared with Nivea, Mentholatum has its 
competitive advantage. First of all, as a US company entering the Chinese market, Mentholatum has made an understanding of Asian women and men's skin to produce skincare products which are suitable for Asians. Secondly, Mentholatum was first known for its production of pharmaceuticals, so Mentholatum's skin-care products contain herbal ingredients, which are safe and effective, and Mentholatum's products are in line with Watsons's sales philosophy, mainly for the production of affordable and effective products for young people. Last but not least, Mentholatum made a lot of advertising when entering the Chinese market, and Mentholatum itself also paid great attention to advertising investment, and Watsons chose to cooperate with Mentholatum and also reduced the cost of publicity for itself. However, the cooperation between Watson Group and Mentholatum is bound to affect the product price and market demand of Nivea, which will greatly reduce the enthusiasm for cooperation with retailers and cause channel conflicts. Since Nivea also has fixed customers, the conflict of supply chain channels will greatly affect the profits of retailers and the whole supply chain, resulting in the instability of the supply chain system.

The above problems have existed in the supply chain system for a long time, especially in the supply chain with competition and cooperation. The impacts include the conflicts of interest between suppliers and retailers, which harm maintaining the healthy, stable, and sustainable development of the supply chain system. To reduce the impact of this phenomenon and realize the coordination and efficient operation of supply chain channels, it is urgent to coordinate the corresponding coordination mechanism. Through investigation, we found that two suppliers in the supply chain, Nivea and Mentholatum, provide homogeneous products, but the products have different brands and have competitive relations. To increase the number of customers and benefits, retailers cooperate with Mentholatum, which has advantages in product positioning, marketing, and customers. Although Mentholatum and Watsons's cooperation is to a certain extent to increase the mutual benefits, it has affected the revenue of Nivea and reduced the enthusiasm for cooperation with the retailer Watsons. Besides, Nivea has stable customers in the field of men's skincare products, which has resulted in the uncertainty or reduction of the revenue of retailers and the supply chain system. For retailers who are eager to explore the market and who want to protect the benefits of their partners, how to find a win-win strategy becomes crucial. Therefore, the research problem of this paper is to find a coordination mechanism that can coordinate the interests of retailers, suppliers, and the whole supply chain.

At present, the research on supply chain conflict mainly realizes the coordination through the design of the corresponding coordination mechanism, which is more common such as profit-sharing [1] and wholesale price contract [2, 3], two-part tariff $[4,5]$ and cost-sharing $[6,7]$, etc. Based on the abovementioned analysis, we know that the close cooperation between Mentholatum and Watsons in information, customers, and product preferences has weakened Nivea's market share, intensified the conflict between Nivea and
Mentholatum, and reduced the cooperation between Nivea and retailers. As a result, the overall supply chain is unstable and inefficient. So, to solve conflict or coordination problems, considering that cooperation effort degrees and competition degrees are important factors on the supply chain members, we construct a two-stage model and then design a coordination mechanism through value-added benefit distribution through group negotiation model.

In this paper, we first analyze the optimal decision of the two-stage supply chain model from the perspective of centralized decision and decentralized decision; the results showed that the optimal retail prices under the centralized decision are lower than those under the decentralized decision, while the optimal product-market demand under the centralized decision is higher than that under the decentralized decision. And the overall profits of the supply chain and the cooperation effort degrees of the Mentholatum under the centralized decision are higher than those under the decentralized decision. Besides, we also obtain that the competitive intensity and price sensitivity have positive and negative effects on the efforts of suppliers and retailers, respectively. And the degree of cooperation between suppliers and retailers affects the profits of supply chain members and the whole supply chain in different degrees. Finally, the proposed value-added profit distribution mechanism can effectively deal with conflict problem and guarantee supply chain members and supply chain to maximize their profits and adopt the centralized decision. Meanwhile, the profits of the supply chain and supply chain members, optimal retail price, and optimal sales volume under the centralized decision are larger than those under the decentralized decision.

The paper is organized as follows. Section 2 discusses the related literature. In Section 3, we formalize the problem, putting forward the basic hypothesis, and constructing the benefit function of each supply chain member in the supply chain. Section 4 presents the analysis of optimal pricing decision-making under the competition relationship and the sensitivity analysis of the pricing strategy, and then we propose the supply chain coordination mechanism of profit distribution under the competition and cooperation relationship. Finally, we offer managerial implications and conclude this research in Section 5.

\section{Literature Review}

Coordination is an important way to solve the problems of the supply chain. To deal with problems, from different aspects and views, more and more scholars have been doing research on supply chain decisions and establishing a coordination mechanism of the supply chain. By combing the existing literature, they proposed some coordination mechanisms from the perspectives of the quantity discount and pricing, information, subsidy policy, profits and costs, and others.

(1) The quantity discount and pricing are factors deciding the supply chain, and some scholars focus on the quantity discount and pricing, and then they 
design coordination mechanism [8-11]. The quantity discounts are to encourage buyers to buy in large quantities at one time and establish long-term trading relationships with themselves [12-15]. Starting with Pasternack's [16] efforts, coordination mechanisms through buy-back and return policies have also received considerable research attention [17-19]. In the process of quantity discount and pricing coordination, supply disruption and uncertain demand can play a greater role in reducing and coordinating the impact on the supply chain $[18,20-23]$. Wholesale price contracts are also a common way to play a positive role in supply chain coordination [24, 25]. Facing the effect of fairness preference on a dyadic supply chain with random capacity and random demand, Lan and Ji [26] established the models of wholesale price contract with random capacity and stochastic demand, and their results indicated that the wholesale price contract could improve the profits of the whole supply chain and coordinate the supply chain. Besides, the wholesale price contract usually serves as the basis for a coordination mechanism or works with other contracts $[2,3,27]$. A two-part tariff is another pricing coordination mechanism $[4,5,28]$. In a two-part tariff, a supplier offers the retailers a constant unit wholesale price and a fixed fee, where the buyer chooses order quantity based on the contract [29].

(2) In supply chain management, we often encounter supply disruptions, symmetric information, and demand uncertainty. Generally speaking, quantity flexibility contracts are often used in supply chain with uncertain risks [30]. Information asymmetry and supply disruptions may cause the less reliable supplier type to stop using backup production [31]. To analyze the centralized or decentralized decisions of supply chain and discuss the influence of information on the supply chain, from quantity flexibility contracts, cooperative advertising, and information sharing [32-36], some scholars design coordination mechanisms. Among them, Heydari and Norouzinasab [37] proposed a discount model to solve demand randomness and price sensitivity. The information sharing can effectively reduce the effect of the uncertain situation $[38,39]$, and then they designed coordination mechanisms [40-42].

(3) Policies play an important role in supply chain management and coordination. In policies, lowcarbon supply policies [43], consumer returns policies [44], and government subsidy policies $[45,46]$ are often used to deal with the coordination problems of green supply chain and closed-loop supply chain. Among them, with the coexistence of the fossil fuel car and electric vehicle supply chains, Zhang and Wang [47] discussed the influence of three kinds of government policies on two competing supply chains under either decentralized or centralized decision making. However, these scholars did not explore the relationship between government subsidy and social welfare. Arya and Mittendorf [48] studied the effect of government subsidy on charitable donations of retailers (a CSR behavior) and found that the subsidy could reduce the degree of double marginalization of the supply chain. Hafezalkotob [49] discussed the impact of government environmental protection policy on the supply chain and regarded that the government's environmental protection policy could reduce the negative business impact on the environment.

(4) A profit-sharing and cost-sharing contract can play an important role in coordinating supply chain members and improving their overall performance [1]. To increase market share and increase profits, Chauhan and Proth [50] proposed a provider-retailer partnership model based on profit sharing. The mixed revenue-sharing option contract (option contract and revenue-sharing contract) have a positive effect on reducing double marginalization effects [51]. In terms of cost sharing, it is often used in combination with other contracts to improve the overall profit of the supply chain. A revenue and promotional cost-sharing contract and a two-part tariff contract can coordinate the sustainable development of the supply chain $[6,7,52]$. Among them, Ghosh and Shah [53] proposed the design of a green cost-sharing contract between retailers and manufacturers to promote the development of green supply chains and cooperation among channel members. Panda [54] analyzed the optimal decisions of the manufacturer and retailer who undertook CSR, respectively, and then proposed a revenuesharing contract to coordinate the supply chain. By combining CSR, product recovery, and channel coordination to specify and quantify the CSR and its impact, Panda and others put forward a revenuesharing contract to resolve the channel conflict of a supply chain [55-58].

The above research discusses the theories and methods of resolving supply chain conflicts in terms of profit, policy, and supply chain management. Besides, some scholars also discuss the role of government subsidies in supply chain coordination. These studies have provided us with some new thinking and inspiration [45]. In recent years, in the process of supply chain operation, the competition among supply chain members, information asymmetry, and supply interruption have become important causes of supply chain conflicts. However, most of these coordination mechanisms are a negotiation and discussion process, and most studies do not clearly show this negotiation and negotiation process.. Therefore, this paper explores how to design the coordination mechanism and realize the coordination of the supply chain through the group negotiation model in a supply chain with competition and cooperation. 
2.1. Research Gaps. To summarize the differences between our paper and the literature, we include Table 1. In short, from the literature review, the following research gaps are identified.

(1) Most previous research studies have not paid enough attention to the competition and cooperation between multiple suppliers and single retailers; they did not even research the impact of supply chain decisions. (2) In terms of the coordination mechanism, most of the literature adopts the existing contract or inherent methods, some of which are directly adopted, such as the means of quantity discount and pricing, information, subsidy policy, profits, and costs. Lack of discussion and research on the coordination mechanism. (3) Although the current literature studies the competition and cooperation in the supply chain system, there is little research on how the degree of competition and cooperation affect each other and the impact of the degree of cooperation and competition on the supply chain system and supply chain members. Based on the above literature analysis and deficiencies, the competition and cooperation relationship between suppliers and retailers was considered in the second-order supply chain we constructed, and the influence of competition degree and cooperation degree on the decision making of supply chain members was explored. Finally, we designed the coordination mechanism of value-added profit distribution based on the group negotiation model.

\section{The Basic Model}

In real life, there exists a variety of large retailers, and their suppliers often provide them some homogeneous products, which form a two-stage supply chain. In the supply chain, the retailer is in a dominant position as a result of possessing the market position and sales experience in the purchasing and sales section, while the suppliers are in a subordinate position, and then the supply chain's decisions follow the Stackelberg game. Assume that there exists a two-stage supply chain with one brand retailer and two competitive contract suppliers. To obtain much more profits and competitive advantages, being the risk-neutral rational decision makers, the retailer will share sale information and cooperate with some suppliers to produce some products, while these suppliers are also willing to do these by inputting some cooperation effort degree. To describe and deal with the supply chain management problems under this condition, in this paper, we will establish some basic models.

In the two-stage supply chain with one brand retailer and two competitive contract suppliers, the retailer to some certain can coordinate her suppliers, while the suppliers provide homogeneous products for the retailer. While supplier 1 can share the retailer's information to jointly produce and fix the price of some products with the retailer, supplier 2 cannot do so (denoted as 1 and 2, respectively). According to the above analysis, assume that there exists a supply chain with one brand retailer and two contract suppliers, and the suppliers provide a kind of homogeneous products. As a result of the differences in brand, production scale, and capacity of the two suppliers, the sale prices and demand for the products from them are different. Let $w_{i}, p_{i}, d_{i}, Q_{i}, \pi_{s i}(i=1,2)$ stand for the wholesale price, retail price, market's total potential demand, actual market demand of the products from supplier $i$, and profits of supplier $i$, respectively. $w_{i}, p_{i}, d_{i}, Q_{i}, \pi_{s i}(i=1,2)$ stand for the wholesale price, retail price, market's total potential demand, actual market demand, and profits of the products from supplier $i$, respectively. In the supply chain, the actual market demand for the products is influenced by the retail price and competition between the suppliers. Generally speaking, the actual market demand has a negative and positive correlation with the retail price and competition among supplier $i$, respectively [45]. Assume that the product market demand or order quantity of product is a linear function over the product price and competition between the suppliers. By referring to Savaskan's approach [59], the expression of the market demand from supplier $i$ under the competition can be written as follows: $d_{i}=Q_{i}-\alpha p_{i}+\beta p_{j}(i=1,2 ; j=3-i)$, where $\alpha, \beta(\beta>0)$ stand for the retail price-sensitive parameter and competition parameter. The greater $\beta$ is, the stronger the competition between the two suppliers is. The influence of the retail price of supplier $i$ 's products on-demand is greater than that of supplier $i$ 's competition on-demand, that is, $\alpha>\beta$.

In the introduction, we talk about the relationship between Watsons and the supplier of homogeneous products which is Mentholatum and Nivea. To grasp the consumer preference, reduce the production cost and tap the potential customer market. Watsons and Mentholatum choose to cooperate in production, in which Watsons provides Mentholatum with customer data, purchasing characteristics, and demand preference of the consumer market, and then Mentholatum accurately produces according to the information provided by the retailers to improve product quality and achieve a win-win situation. But such behavior harms Nivea and the supply chain. To describe the above situation, we improve the model and make it representative. Firstly, considering that the cooperative production between retailers and suppliers in the above situation can tap the potential market demand and improve the business level, we introduce the concept of cooperative production into the demand function and use $s$ to represent the degree of cooperation between them. Let $k$ express supplier $i$ 's cooperation effort parameter on cost and consider that the cooperation and investment between suppliers and retailers have a greater impact on costs than the sensitivity of consumers to price, so we have $k>\alpha$. Let $\lambda, C(s)(0<\lambda<1)$ influence coefficient on product market demand and cooperation effort cost, respectively. According to the above analysis, the product demand function with cooperation effort degrees and competition of supplier $i$ can be rewritten as

$$
d_{i}=Q_{i}-\alpha p_{i}+\beta p_{j}+\lambda s, \quad(i=1,2 ; j=3-i)
$$

Let $C(s)$ indicate supplier 1's cooperation effort cost; according to the research of relevant scholars $[60,61]$, its expression can be written as $C(s)=k s^{2} / 2$. Assume that $\pi_{r}, \pi$ stand for the profits of the retailer and supply chain. 
TABLe 1: Our paper vs. literature.

\begin{tabular}{|c|c|c|c|}
\hline Author & $\begin{array}{l}\text { The background of supply chain } \\
\text { coordination }\end{array}$ & $\begin{array}{l}\text { Coordination } \\
\text { mechanism }\end{array}$ & Focus \\
\hline Yang et al. [31] & $\begin{array}{l}\text { Supply disruptions and information } \\
\text { asymmetry }\end{array}$ & $\begin{array}{c}\text { A backup } \\
\text { production option }\end{array}$ & $\begin{array}{l}\text { Whether the risk management strategies will have } \\
\text { an effect on the manufacturer's change }\end{array}$ \\
\hline Giri and Bardhan [21] & $\begin{array}{c}\text { Supply disruption and uncertain } \\
\text { demand. }\end{array}$ & Buyback contract & $\begin{array}{l}\text { Coordinate the order quantity and the service level } \\
\text { (SL) }\end{array}$ \\
\hline Hafezalkotob [49] & Green supply and competition & $\begin{array}{l}\text { Price competition } \\
\text { model }\end{array}$ & $\begin{array}{l}\text { Environmental protection and revenue seeking } \\
\text { policies of government }\end{array}$ \\
\hline Du et al. [43] & Low-carbon supply & $\begin{array}{l}\text { A Stackelberg-like } \\
\text { model }\end{array}$ & $\begin{array}{c}\text { Environment protection and supply chain } \\
\text { operations }\end{array}$ \\
\hline $\begin{array}{l}\text { Heydari and Ghasemi } \\
{[22]}\end{array}$ & $\begin{array}{l}\text { Stochastic quality of returned } \\
\text { products and uncertain } \\
\text { remanufacturing capacity }\end{array}$ & A revenue sharing & Reverse supply chain coordination \\
\hline $\begin{array}{l}\text { Heydari and } \\
\text { Norouzinasab [37] }\end{array}$ & $\begin{array}{l}\text { The supply chain under stochastic } \\
\text { price-sensitive demand }\end{array}$ & $\begin{array}{l}\text { A two-level } \\
\text { discount model }\end{array}$ & Coordinate pricing and ordering decision \\
\hline Hou et al. [18] & Supply disruption & Buy-back contract & The pricing strategy between demand interruption \\
\hline Huang et al. [38] & $\begin{array}{l}\text { Pricing competition and cooperation } \\
\text { in supply chain }\end{array}$ & $\begin{array}{l}\text { Decentralized game } \\
\text { models }\end{array}$ & $\begin{array}{l}\text { How pricing strategies and power structures affect } \\
\text { supply chain members' performance }\end{array}$ \\
\hline Lan and Ji [26] & $\begin{array}{l}\text { The supply chain under random } \\
\text { capacity and random demand }\end{array}$ & $\begin{array}{l}\text { Wholesale price } \\
\text { contract }\end{array}$ & $\begin{array}{c}\text { Investigates the effect of fairness preference on a } \\
\text { dyadic supply chain }\end{array}$ \\
\hline Panda [54] & Socially responsible supply chain & $\begin{array}{l}\text { Revenue sharing } \\
\text { contract }\end{array}$ & Coordination of a socially responsible supply chain \\
\hline Seifert et al. [10] & A three-echelon supply chain & $\begin{array}{l}\text { Price-only } \\
\text { contracts }\end{array}$ & $\begin{array}{l}\text { Coordination in a three-echelon supply chain and } \\
\text { examination of the impact of subsupply chain } \\
\text { coordination (sub-coordination). }\end{array}$ \\
\hline Wang et al. [25] & $\begin{array}{l}\text { Supply chain under the endogenous } \\
\text { information structure }\end{array}$ & $\begin{array}{l}\text { Wholesale-price } \\
\text { contract }\end{array}$ & $\begin{array}{c}\text { Cost of information' } s \text { influence on the order } \\
\text { quantity and wholesale price }\end{array}$ \\
\hline Our paper & Cooperation and competition & $\begin{array}{l}\text { Profit distribution } \\
\text { mechanism }\end{array}$ & Pricing, demand, and benefit coordination \\
\hline
\end{tabular}

According to the above discussion and analysis, all the parameters and variables used in our model are listed in Table 2, and the profits of the retailer, two suppliers, and supply chain can be expressed as

$$
\begin{aligned}
& \pi_{r}=\left(p_{1}-w_{1}\right) d_{1}+\left(p_{2}-w_{2}\right) d_{2}, \\
& \pi_{s 1}=\left(w_{1}-c_{1}\right) d_{1}-C(s)=\left(w_{1}-c_{1}\right)\left(Q_{1}-\alpha p_{1}+\beta p_{2}+\lambda s\right)-\frac{k s^{2}}{2},
\end{aligned}
$$$$
\pi_{s 2}=\left(w_{2}-c_{2}\right) d_{2}=\left(w_{2}-c_{2}\right)\left(Q_{1}-\alpha p_{2}+\beta p_{1}\right),
$$$$
\pi=\pi_{r}+\pi_{s 1}+\pi_{s 2} \text {. }
$$

\section{A Coordination Mechanism through Benefit Distribution}

In the supply chain with one brand retailer and two contract suppliers, there exists a variety of conflict problems. To deal with the problems, a suitable coordination mechanism should be established.

4.1. The Optimal Pricing Decisions of Supply Chain. To construct a much more effective pricing coordination mechanism, we first analyze the pricing decisions of the supply chain. Since the supply chain's decisions follow the
Stackelberg game, we will discuss the optional pricing decisions under the decentralized and centralized decision.

4.1.1. The Optimal Decisions under the Decentralized Decision. For the supply chain, based on the Stackelberg game, its decentralized decision can be divided into two stages. Firstly, the retailer decides on the ordering quantity and the sale prices of the two kinds of suppliers, and then the suppliers make decisions on the wholesale prices and cooperation effort degrees. Let $\pi_{r}, \pi_{s i}(i=1,2)$, and $\pi$ represent the retailer, supplier, and the supply chain total profits, respectively. The specific decision-making process is analyzed as follows.

(1) The Retailer's Optimal Decisions. According to the formulas (1) and (2), the retailer's maximization profits can be expressed as follows:

$$
\begin{aligned}
\max \pi_{r}= & \left(p_{1}-w_{1}\right)\left(Q_{1}-\alpha p_{1}+\beta p_{2}+\lambda s\right) \\
& +\left(p_{2}-w_{2}\right)\left(Q_{2}-\alpha_{2} p_{2}+\beta p_{1}\right) .
\end{aligned}
$$

Theorem 1. Assume that $p_{i}^{d}, d_{i}^{d}, i=1,2$ represent the retail price and product market demand of supplier $i$ under the decentralized decision, respectively. If there exists a set of unique values $p_{i}^{d *}, d_{i}^{d *}$ to maximize the expected profits of the retailer, then the optimal decisions of the retailer can be obtained as follows: 
TABLE 2: Decision variables and parameters.

\begin{tabular}{|c|c|}
\hline Parameters and variables & Meaning \\
\hline$\beta$ & Supplier's competition parameter \\
\hline$p_{i}$ & Price of supplier $i$ 's products \\
\hline$\alpha$ & Consumer sensitivity to price \\
\hline$s_{i}$ & Supplier's cooperation input \\
\hline$k$ & The supplier's cooperative investment parameter \\
\hline$\lambda_{i}$ & The impact of cooperative alliance on market demand \\
\hline$w_{i}$ & Wholesale price of supplier $i$ \\
\hline$Q_{i}$ & The market's total potential demand for products of supplier $i$ \\
\hline$\pi$ & Total profit of supply chain \\
\hline$\pi_{s i}^{d *}$ & The maximization profits of supplier $i$ under the decentralized decision \\
\hline$p_{i}^{d *}, d_{i}^{d *}, s_{i}^{d *}, w_{i}^{d *}$ & The optimal decisions of the supply chain under the centralized decision \\
\hline$p_{i}^{c *}, d_{i}^{c *}, s_{i}^{c *}, w_{i}^{c *}$ & The optimal decisions of the supply chain under the decentralized decision \\
\hline$\pi_{i}^{h}(i=r, s 1, s 2)$ & The upper limit of coordination subsidy of the retailer, supplier 1 , and supplier 2 \\
\hline$\pi_{r}^{n}$ & The profit of the retailer after coordination \\
\hline$\pi_{s i}^{n}$ & Supplier $i$ 's profit after coordination \\
\hline$\Delta \pi$ & The value-added portion of the supply chain \\
\hline$\Delta \pi \prime$ & Residual profit after the first distribution \\
\hline$\theta_{s i}$ & Supplier $i$ s contribution to the value-added portion of the supply chain \\
\hline$\rho$ & The coordinate coefficient of satisfaction of the system \\
\hline$\eta_{i}(i=r, s 1, s 2)$ & The market weight or bargaining power of the dominant retailer and the two suppliers \\
\hline
\end{tabular}

$$
\begin{aligned}
& p_{1}^{d *}=\frac{\left(\beta^{2}-\alpha^{2}\right) w_{1}+\alpha\left(Q_{1}+\lambda s\right)-\beta Q_{2}}{2\left(\beta^{2}-\alpha^{2}\right)}, \\
& p_{2}^{d *}=\frac{\left(\beta^{2}-\alpha^{2}\right) w_{2}-\beta\left(Q_{1}+\lambda s\right)-\alpha Q_{1}}{2\left(\beta^{2}-\alpha^{2}\right)}, \\
& d_{1}^{d *}=\frac{\beta w_{2}-\alpha w_{1}+\lambda s+Q_{1}}{2}, \\
& d_{2}^{d *}=\frac{\beta w_{1}-\alpha w_{2}+Q_{2}}{2} .
\end{aligned}
$$

Because $\alpha>0, \beta>0$, the influence of the retail price of supplier $i$ 's products on-demand is greater than that of supplier $i$ 's competition on-demand, that is, $\alpha>\beta$. So,

$$
H\left(p_{1}, p_{2}\right)=\left[\begin{array}{cc}
-2 \alpha & 2 \beta \\
2 \beta & -2 \alpha
\end{array}\right]=4\left(\alpha^{2}-\beta^{2}\right),
$$

such that $H\left(p_{1}, p_{2}\right)>0$, and then $\pi_{r}$ is the strict concave function over $p_{1}, p_{2}$, which shows that there exists a unique optimal solution to satisfy formula (5). By combing formulas (8) and (9), we obtain the optional retail prices under the decentralized decision as follows:

$$
\begin{aligned}
& p_{1}^{d *}=\frac{\left(\beta^{2}-\alpha^{2}\right) w_{1}+\alpha\left(Q_{1}+\lambda s\right)-\beta Q_{2}}{2\left(\beta^{2}-\alpha^{2}\right)}, \\
& p_{2}^{d *}=\frac{\left(\beta^{2}-\alpha^{2}\right) w_{2}-\beta\left(Q_{1}+\lambda s\right)-\alpha Q_{1}}{2\left(\beta^{2}-\alpha^{2}\right)} .
\end{aligned}
$$

Proof. According to the inverse induction method, for formula (4), by solving its first-order partial derivative over $p_{1}, p_{2}$ and making it equal to zero, we can obtain the following:

$$
\begin{aligned}
& p_{1}^{d}=\frac{\alpha w_{1}+2 \beta p_{2}-\beta w_{2}+\lambda s+Q_{1}}{2 \alpha}, \\
& p_{2}^{d}=\frac{\alpha w_{2}+2 \beta p_{1}-\beta w_{1}+Q_{2}}{2 \alpha} .
\end{aligned}
$$

Then, by solving the second-order partial derivative of formula (4) over the variable $p_{1}, p_{2}$, we can obtain its Hessian matrix over $p_{1}, p_{2}$ as follows:

$$
H\left(p_{1}, p_{2}\right)=\left[\begin{array}{cc}
\frac{\partial^{2} \pi_{r}}{\partial p_{1}^{2}} & \frac{\partial^{2} \pi_{r}}{\partial p_{1} p_{2}} \\
\frac{\partial^{2} \pi_{r}}{\partial p_{2} p_{1}} & \frac{\partial^{2} \pi_{r}}{\partial p_{2}^{2}}
\end{array}\right]=\left[\begin{array}{cc}
-2 \alpha & 2 \beta \\
2 \beta & -2 \alpha
\end{array}\right] .
$$

Then, we can determine the optional product market demand of the suppliers as follows:

$$
\begin{aligned}
& d_{1}^{d *}=\frac{\beta w_{2}^{d *}-\alpha w_{1}^{d *}+\lambda s^{d *}+Q_{1}}{2}, \\
& d_{2}^{d *}=\frac{\beta w_{1}^{d *}-\alpha w_{2}^{d *}+Q_{2}}{2} .
\end{aligned}
$$

Therefore, the retailer's optimal decisions can be determined. QED.

According to the retailer's optimal decisions, we can obtain the maximization profits of two suppliers as follows:

$$
\begin{aligned}
& \pi_{s 1}=\left(w_{1}-c_{1}\right)\left(Q_{1}-\alpha p_{1}+\beta p_{2}+\lambda s\right)-\frac{k s^{2}}{2}, \\
& \pi_{s 2}=\left(w_{2}-c_{2}\right)\left(Q_{2}-\alpha p_{2}+\beta p_{1}\right) .
\end{aligned}
$$


(2) The Supplier's Optimal Decisions. According to the retailer's decisions and expressions (3) and (4), the maximization profits of suppliers 1 and 2 under the decentralized decision can be written as

$$
\begin{aligned}
& \max \pi_{s 1}=\left(w_{1}-c_{1}\right) \cdot \frac{\beta w_{2}-\alpha w_{1}+\lambda s+Q_{1}}{2}-\frac{k s^{2}}{2}, \\
& \max \pi_{s 2}=\left(w_{2}-c_{2}\right) \cdot \frac{\beta w_{1}-\alpha w_{2}+Q_{2}}{2} .
\end{aligned}
$$

Theorem 2. Assume that $w_{1}^{d}, w_{2}^{d}, s^{d}$ express the wholesale price of the two suppliers and cooperation effort degree of supplier 1, respectively. If there exist unique values $w_{1}^{d *}, w_{2}^{d *}, s^{d *}$ to maximize their expected profits, then they will satisfy the following:

$$
\begin{aligned}
w_{1}^{d *} & =\frac{\beta w_{2}+\alpha c_{1}+\lambda s^{d *}+Q_{1}}{2 \alpha}, \\
w_{2}^{d *} & =\frac{2 k c_{2}\left(\beta^{2}-2 \alpha^{2}\right)+\lambda^{2}\left(\beta c_{1}+\alpha_{2} c_{2}+Q_{2}\right)-2 \beta k\left(\alpha c_{1}+Q_{2}\right)-4 k \alpha^{2}}{4 k\left(\beta^{2}-2 \alpha^{2}\right)+2 \lambda^{2} \alpha}, \\
s^{d *} & =\frac{\left(\beta w_{2}^{d *}-\alpha c_{1}+Q_{1}\right) \lambda}{4 k \alpha-\lambda^{2}} .
\end{aligned}
$$

Proof. According to the above formula, we need to judge whether formulas (15) and (16) have the optimal value, as shown below:

$$
H\left(w_{1}, s\right)=\left[\begin{array}{ll}
\frac{\partial^{2} \pi_{s 1}}{\partial w_{1}^{2}} & \frac{\partial^{2} \pi_{s 1}}{\partial w_{1} \partial s} \\
\frac{\partial^{2} \pi_{s 1}}{\partial s^{2}} & \frac{\partial^{2} \pi_{s 1}}{\partial s \partial w_{1}}
\end{array}\right]=\left[\begin{array}{cc}
-\alpha & \frac{\lambda}{2} \\
-k & \frac{\lambda}{2}
\end{array}\right] .
$$

Based on the basic model part of the analysis, we know that $k>\alpha$, and $\left[\begin{array}{ll}-\alpha & \lambda / 2 \\ -k & \lambda / 2\end{array}\right]=(\lambda / 2)(k-\alpha)$, so $H\left(w_{1}, s\right)>0$, and then $\pi_{s 1}$ is the strict concave function over $w_{1}, s$, which shows that there exists a unique optimal solution to satisfy formula (15). We also obtain $\partial^{2} \pi_{s 2}^{d} / \partial w_{2}=-\alpha<0$, and supplier 2 also has a unique optimal solution to satisfy formula (16).

According to the inverse induction method, the optimal solutions of supplier 1 can be solved. Firstly, by solving the first-order partial derivative of formula (15) over $s$ and $w_{1}$ and making it be zero, we can obtain $w_{1}^{d}=\left(\beta w_{2}+\alpha c_{1}+\right.$ $\left.\lambda s+Q_{1}\right) / 2 \alpha$ and $s^{d}=\left(w_{1}-c_{1}\right) \lambda / 2 k$. By computing the second-order partial derivative of formula (15) over $s$ and $w_{1}$, we determine $\partial^{2} \pi_{s 1}^{d} / \partial w_{1}^{2}<0, \partial^{2} \pi_{s 1}^{d} / \partial s^{2}<0$, that is to say, $\pi_{s 1}^{d}$ is the concave function over $s$ and $w_{1}$, which shows that there exist uniquely determined values $w_{1}^{d *}, s^{d *}$ to maximize $\pi_{s 1}^{d}$. Then, we substitute them into expression (16) and take the above similar computing so that we can determine the optional wholesale price of supplier 2 .

$$
w_{2}^{d}=\frac{2 k c_{2}\left(\beta^{2}-2 \alpha^{2}\right)+\lambda^{2}\left(\beta c_{1}+\alpha_{2} c_{2}+Q_{2}\right)-2 \beta k\left(\alpha c_{1}+Q_{2}\right)-4 k \alpha^{2}}{4 k\left(\beta^{2}-2 \alpha^{2}\right)+2 \lambda^{2} \alpha} .
$$

Therefore, the suppliers' optimal decisions can be obtained. QED.

Proposition 1. Under the decentralized decision, the higher the cooperation effort degrees of supplier 1, the higher the retail prices of the two products, the higher the product market demand of supplier 1, the lower the order quantity of supplier 2, and the greater the profits of the retailer and suppliers.

Proof. By solving the first-order partial derivative of the retail prices, the order quantity, and the profits of the supply chain members over the cooperation effort degrees of supplier 1 , we can obtain the following: 


$$
\begin{aligned}
& \frac{\partial p_{1}}{\partial s}=-\frac{3 \beta^{2} \lambda \alpha-6 \lambda \alpha^{3}}{2\left(\beta^{2}-4 \alpha^{2}\right)\left(\beta^{2}-\alpha^{2}\right)} \\
& \frac{\partial p_{2}}{\partial s}=-\frac{2 \beta^{3} \lambda-5 \lambda \alpha^{2}}{2\left(\beta^{2}-4 \alpha^{2}\right)\left(\beta^{2}-\alpha^{2}\right)} \\
& \frac{\partial d_{1}}{\partial s}=-\frac{\lambda \alpha^{2}}{\beta^{2}-4 \alpha^{2}} \\
& \frac{\partial d_{2}}{\partial s}=-\frac{\beta \lambda \alpha}{\beta^{2}-4 \alpha^{2}} \\
& \frac{\partial \pi_{r}}{\partial s}=-\frac{\lambda \alpha^{2}\left[\left(\beta^{4}-4 \alpha^{4}\right)+\lambda s \alpha\left(5 \beta^{2}+4 \alpha^{2}\right)+4 \beta \alpha\left(\beta^{2}-\alpha^{2}\right)+4 \beta Q_{2}\left(\beta^{2}+8 \alpha^{2}\right)\right]}{2\left(\beta^{2}-4 \alpha^{2}\right)\left(\beta^{2}-\alpha^{2}\right)} \\
& +\frac{\lambda \alpha^{2}\left[Q_{1} \alpha_{2}\left(5 \beta^{2}+4 \alpha^{2}\right)+3 \beta^{3} \alpha^{2} c_{1}\right]}{2\left(\beta^{2}-4 \alpha^{2}\right)\left(\beta^{2}-\alpha^{2}\right)} \\
& \frac{\partial \pi_{s 1}}{\partial s}=-\frac{s k\left(\beta^{2}-4 \alpha^{2}\right)^{2}+2 \lambda c_{1} \alpha^{2}\left(2 \alpha^{2}-\beta^{2}\right)-2 \beta \lambda \alpha^{2}\left(\alpha c_{2}-Q_{2}\right)-4 \lambda \alpha Q_{2}^{2}\left(\lambda e+Q_{1}\right)}{\left(\beta^{2}-4 \alpha^{2}\right)^{2}}, \\
& \frac{\partial \pi_{s 2}}{\partial s}=\frac{\beta \lambda \alpha\left[c_{2}\left(\beta^{2}-2 \alpha^{2}\right)+\beta\left(\lambda s+Q_{1}\right)+\alpha\left(\beta c_{1}+2 Q_{2}\right)\right]}{\left(\beta^{2}-4 \alpha^{2}\right)^{2}} .
\end{aligned}
$$

Because $\alpha>0, \beta>0, \alpha>\beta, 0<\lambda<1, k>0$, the following conditions hold: $\partial p_{1} / \partial s>0, \partial p_{2} / \partial \quad s>0, \partial d_{1} / \partial s>0, \partial d_{2} /$ $\partial s<0, \partial \pi_{r} / \partial s>0, \partial \pi_{s 1} / \partial s>0, \partial \pi_{s 2} / \partial s>0$. Therefore, the conclusions can be given. QED.
Assume that $\pi^{c}$ indicates the profits of the supply chain. According to formula (5), the maximization profits of the supply chain under the centralized decision can be expressed as

\subsubsection{The Optimal Decisions under the Centralized Decision.}

$$
\begin{aligned}
\max \pi & =\pi_{r}+\pi_{s 1}+\pi_{s 2} \\
& =\left(p_{1}-c_{1}\right)\left(Q_{1}-\alpha p_{1}+\beta p_{2}+\lambda s\right)+\left(p_{2}-c_{2}\right)\left(Q_{2}-\alpha p_{2}+\beta p_{1}\right)-\frac{k s^{2}}{2} .
\end{aligned}
$$

Theorem 3. In a two-stage supply chain with one dominant retailer and a contract supplier, assume that $p_{i}^{c}, s^{c}, d_{i}^{c}$ stand for as the retail price, cooperation effort degrees, and order quantity of the two-stage supply chain under the centralized decision. When $\alpha-\beta>\lambda^{2} \alpha / 2 k(\alpha+\beta)$, there exists a set of unique values $p_{i}^{c *}, s^{*}, d_{i}^{c *}$ to maximize the expected profits of the supply chain, and then the optimal decisions of the retailer can be expressed as follows:

$$
\begin{aligned}
& p_{1}^{c *}=\frac{k c_{1}\left(\beta^{2}-\alpha^{2}\right)-k\left(\beta Q_{2}+\alpha Q_{1}\right)+\lambda^{2} \alpha c_{1}}{2 k\left(\beta^{2}-\alpha^{2}\right)+\lambda^{2} \alpha}, \\
& p_{2}^{c *}=\frac{2 k c_{1}\left(\beta^{2}-\alpha^{2}\right)+\lambda^{2}\left(\beta c_{1}-\alpha c_{2}+Q_{2}\right)-2 k\left(\beta Q_{1}+\alpha Q_{2}\right)}{2\left[2 k\left(\beta^{2}-\alpha^{2}\right)+\lambda^{2} \alpha\right]},
\end{aligned}
$$




$$
\begin{aligned}
& d_{1}^{c *}=\frac{\beta c_{2}+Q_{1}-\alpha c_{1}+\lambda s^{c *}}{2}, \\
& d_{2}^{c *}=\frac{\beta c_{1}+Q_{2}-\alpha c_{2}}{2}, \\
& s^{c *}=-\frac{\left[\left(\beta^{2}-\alpha^{2}\right) c_{1}+\beta Q_{2}+Q_{1} \alpha\right] \lambda}{2 k\left(\beta^{2}-\alpha^{2}\right)+\lambda^{2} \alpha} .
\end{aligned}
$$

Proof. According to formula (21), we need to judge the convexity of Max $\pi$ for $p_{1}, p_{2}, Q_{1}, Q_{2}$ and $s$ to determine whether there is an optimal variable under the centralized decision. So, we get the Hessian matrix for $\max \pi$, as shown below:

$$
H\left(p_{1}, p_{2}, s\right)=\left[\begin{array}{ccc}
\frac{\partial^{2} \pi}{\partial p_{1}^{2}} & \frac{\partial^{2} \pi}{\partial p_{1} \partial p_{2}} & \frac{\partial^{2} \pi}{\partial p_{1} \partial s} \\
\frac{\partial^{2} \pi}{\partial p_{2} \partial p_{1}} & \frac{\partial^{2} \pi}{\partial p_{2}^{2}} & \frac{\partial^{2} \pi}{\partial p_{2} \partial s} \\
\frac{\partial^{2} \pi}{\partial s \partial p_{1}} & \frac{\partial^{2} \pi}{\partial s \partial p_{2}} & \frac{\partial^{2} \pi}{\partial s^{2}}
\end{array}\right] .
$$

So, we know that from formula $(24),[-2 \alpha]<0$, $\left[\begin{array}{cc}-2 \alpha & 2 \beta \\ 2 \beta & -2 \alpha\end{array}\right]=4(\alpha+\beta)(\alpha-\beta)>0$, and $\left[\begin{array}{ccc}-2 \alpha & 2 \beta & \lambda \\ 2 \beta & -2 \alpha & 0 \\ \lambda & 0 & -k\end{array}\right]=$ $\left(-4 \alpha^{2}+4 \beta^{2}\right) k+2 \lambda^{2} \alpha$, because $k>\alpha>\beta>0$ and $0<\lambda<1$, we must guarantee $\left(-4 \alpha^{2}+4 \beta^{2}\right) k+2 \lambda^{2} \alpha<0$, and then we can get a set of unique values $p_{i}^{c *}, s^{*}, d_{i}^{c *}$ to maximize the expected profits of the supply chain. Then, in this case, we set the first derivative of $\max \pi$ for $p_{1}, p_{2}$ and $s$ equal to 0 , and then we set the system of simultaneous equations to get the optimal value. The process of finding the optimal value is similar to Theorem 1. Hence, the proof is omitted.

Proposition 2. By comparing the optional decisions under the decentralized and centralized decision, there exist the following conclusions.

(1) The optimal retail prices under the centralized decision are lower than those under the decentralized decision, while the optimal product-market demand under the centralized decision is higher than that under the decentralized decision. That is, $p_{1}^{c *}<p_{1}^{d *}$, $p_{2}^{c *}<p_{2}^{d *}, d_{1}^{c *}>d_{1}^{d *}, d_{2}^{c *}>d_{2}^{d *}$.

(2) The overall profits of the supply chain and the cooperation effort degrees of supplier 1 under the centralized decision are higher than those under the decentralized decision. That is, $\pi^{c *}>\pi^{d *}, s^{c *}>s^{d *}$.

Proof. By comparing the optional decision values under the decentralized and centralized decision, we can easily determine the conclusions. Hence, the proof is omitted.

According to the above analysis, when two suppliers choose to cooperate with the retailer at the same time, the overall profits of the supply chain under the centralized decision are higher than those under the decentralized decision making. To achieve the results of the centralized decision, through her dominant position in the supply chain, the retailer often takes some measures to coordinate the suppliers in the process of pricing, so that it is necessary to design a mechanism to guide two suppliers to accept the centralized decision pricing to maintain the long-term stable and sustainable development and overall profits of the supply chain.

4.2. Sensitivity Analysis of the Optimal Decisions under Different Conditions. To directly reflect the influence of the parameters on cooperation effort degrees and the influence of cooperation effort degrees on the profits of the supply chain, we conduct a numerical study by taking $Q_{1}=10, Q_{2}=10, c_{1}=2.5, c_{2}=1.5$.

4.2.1. The Effect of Relevant Parameters on the Cooperation Effort Degrees. In this section, we firstly analyze the effects of $\alpha, \beta, k, \lambda$ on the cooperation effort degrees. According to the conditions, by changing the values of $\alpha, \beta, k, \lambda$, we can make the changing chart of the cooperation effort degrees of supplier 1 over the related parameters, as shown in Figure 1.

According to Figure 1, the price sensitivity parameter and cooperation effort parameter on cost each increase, and the cooperation effort degrees of supplier 1 will decrease. With the increase of competition intensity $\beta$ and influence coefficient on product market demand, the cooperation effort degrees of supplier 1 will enhance. Then, for supplier 1 , the influence degrees of the price sensitivity parameter on the cooperation effort degrees are higher than those of the competition intensity on the cooperation effort degrees. The higher the price sensitivity is, the lower the cooperation degree is. The price sensitivity mainly reflects the consumers' sensitivity to the final retail price; the higher the product sensitivity is, the higher the cooperation cost will be. Therefore, the higher the price sensitivity is, the lower the cooperation effort degrees are. The more the competition intensity is, the higher the cooperation effort degrees are. With the increase of the competition intensity, the product market demand of the suppliers will increase. The more the unit cooperation cost is, the lower the cooperation effort degrees are. The cooperation effort degrees will be gradually reduced as a result of the higher cost of investment and considering the interests and cost of investment and other issues. The greater the influence coefficient on market demand is, the higher the cooperation effort degrees are. With the deepening of the cooperation between the supplier and retailer, the market demand of the cooperative products will increase so that the suppliers are willing to input much more cooperation effort degrees.

\subsubsection{The Influence of Cooperation Effort Degrees on Profits.} Taking the relevant parameters as $\alpha=1, \beta=0.4, k=0.5, \lambda=0.5$ and setting the range of the cooperation effort degree $s$ to be $[0,3]$, we could draw the 


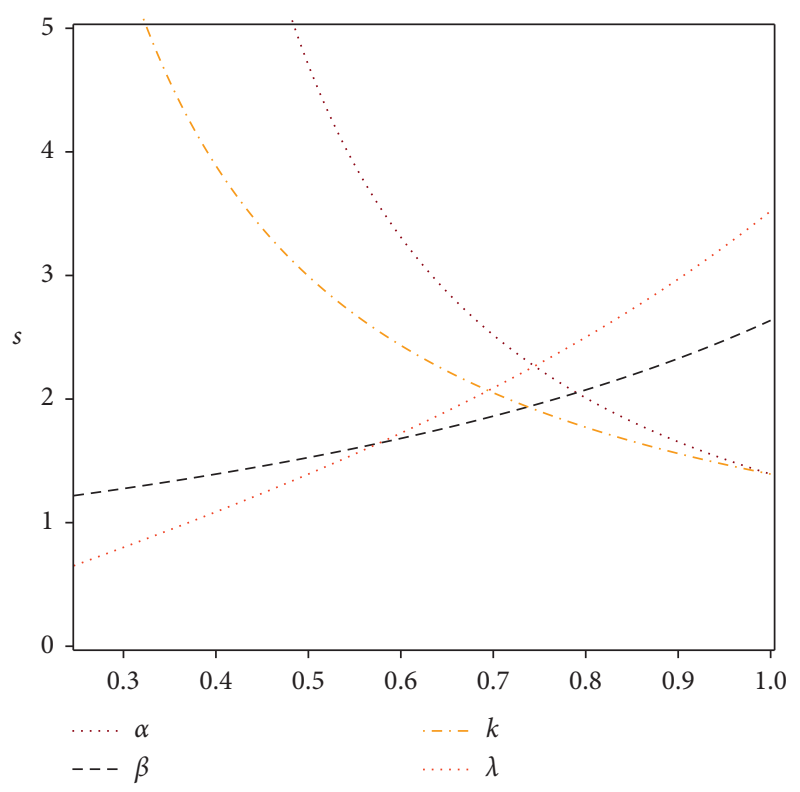

Figure 1: Influence of relevant parameters on the cooperation effort degrees.

changes of the profits of the supply chain members and the supply chain over the cooperation effort degrees between supplier 1 and retailer under the competition and cooperation, as shown in Figure 2.

According to Figure 2, with the increase of the cooperation effort degrees, there exist the following conclusions. Under decentralized decision making, with the increase of the cooperation effort degrees of supplier 1 , the profits of supplier 1 will increase first and then decrease. Therefore, it can be known that when supplier 1's cooperation efforts are in a moderate range $(s \in[1 \sim 2])$, the effect obtained by supply chain 1 is better. If the cooperation effort degrees exceed the moderate degrees, then the cooperation cost will be too large, which results in the loss of the profits. Under the decentralized decision, the more the cooperation effort degrees of supplier 1, the more the profits of supplier 2. With the increase of the cooperation effort degrees of supplier 1, the products will have greater brand benefits, which drives the sales volume of supplier 2 and increases the profits of supplier 2 . With the increase of the cooperation effort degrees of supplier 1 , the retailer's profits will increase. The retailer's profits mainly come from the sale of the products provided by two suppliers; when supplier 1 inputs much more cooperation effort degrees, the products of the suppliers will have a better brand benefit, and then it will result in much more sales of the products and profits. With increase of the cooperation effort degrees of supplier 1, under the decentralized decision or centralized decision, the overall profits of the supply chain will increase; at the same time, no matter the cooperation effort degrees are high or low, the overall profits of the supply chain under the centralized decision are higher than those under the decentralized decision, which further proves Proposition 2. When the supply chain members input much more cooperation effort degrees, although it will

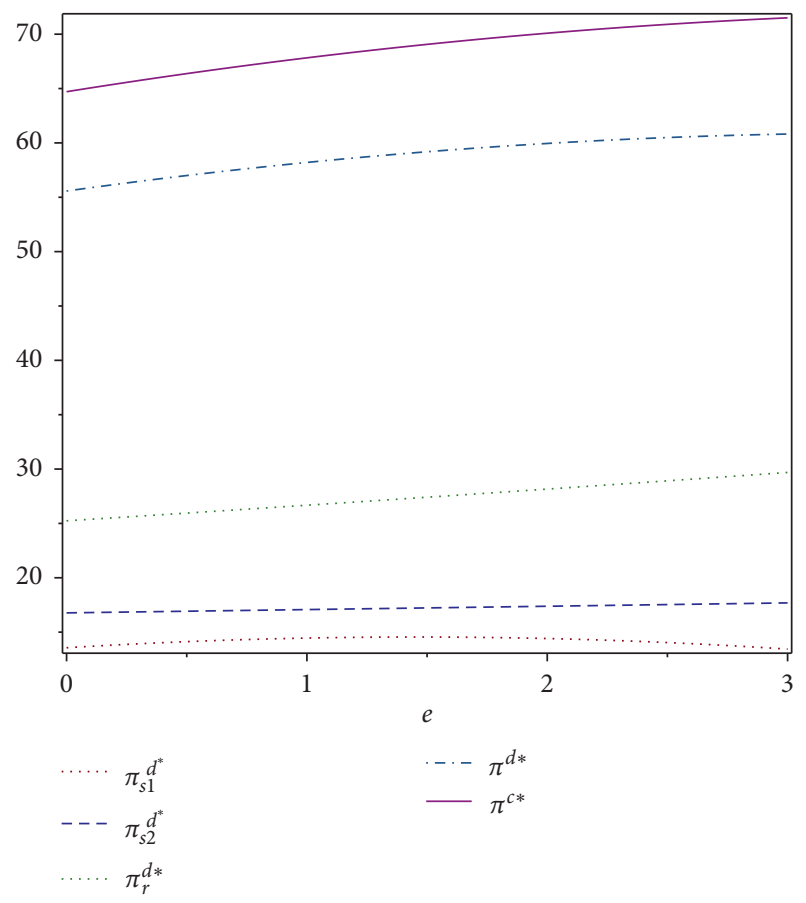

FIgURE 2: The influence of cooperation effort degrees on profits.

produce more costs, the quality and popularity of the products will be higher, which will drive the sales volume of the products in the market to some extent and lead to higher acceptance, thus increasing the overall profits of the supply chain.

4.3. A Coordination Mechanism through Profit Distribution. With the continuous expansion of the supply chain in real life, the relationship of supply chain upstream and downstream is no longer a simple relationship between the buyer and the seller, and there are certainly competitive and cooperative relationships. In the two-stage supply chain with one brand retailer and two competitive contract suppliers, the retailer is closer to the market, and then she can obtain more comprehensive and authentic market sales terminal information, consumer preferences, and other information in the first time so that she can quickly respond to market changes. For the suppliers, they provide homogeneous products for the retailer. To obtain much more profits, supplier 1 is willing to jointly produce and fix the price of some products with the retailer by sharing the retailer's information, but supplier 2 cannot do so. However, the cooperation effort degrees of supplier 1 will increase her original production cost, and then its final profits may reduce with the increase of the cooperation effort degrees. Meanwhile, the overall profits of supply chain members and the optional decisions under the centralized decision are higher than those under the decentralized decision, so the supply chain is inclined to make centralized decisions. To deal with the conflict in the process of supply chain decision, the retailer and supply chain often takes some appropriate subsidies to guide the suppliers to accept the centralized decision. This subsidy 
usually comes from the distribution of profits. In this section, considering that the profit distribution process is a negotiation process, based on the group negotiation model and profit distribution, we attempt to design a coordination mechanism.

For the supply chain members, if they are willing to implement the centralized decision, then their profits are larger than the profits under the decentralized decision. To bulge supply chain members' enthusiasm and take incentive effects, considering the status of the supply chain members and their contribution to the profits of supply chain situation, we can separate the profits of the supply chain members under the centralized decision into the profits under the decentralized decision and valueadded profits, and the suppliers' profits under the decentralized decision are the beginning of the supply chain members' negotiations, and then we exploit the value-added profit distribution and optimization model to coordinate conflict. The coordination process can be divided into two steps. The first step is to obtain relatively satisfactory negotiation profits under the decentralized decision based on the optimization negotiation of the satisfaction of supply chain members. Based on the first step, the second step is to distribute surplus profits or value-added profits under the centralized decision according to the contribution degrees of the supply chain members to secondary distribution. Then, the specific decision process is as follows.

Assume that $\Delta \pi$ expresses the value-added profits of the supply chain, and $\Delta \pi=\pi^{c *}-\pi^{d *}$, while $\pi_{r}^{n}, \pi_{s 1}^{n}, \pi_{s 2}^{n}$ express the members' profits after the coordination under the centralized decision, $\delta_{i}(i=r, s 1, s 2)$ indicates the market weight or bargaining power of the dominant retailer and the two suppliers, and $\pi_{i}^{h}(i=r, s 1, s 2)$ stands for the upper limit of coordination subsidy of the supply chain. As a result of pursuing profit maximization, under the centralized decision, all the supply chain members want much more valueadded profits. To measure its highest satisfaction, supply chain members will take the optimal wholesale price and quantity under the decentralized and centralized decision to calculate their profits. According to the given statement, the highest satisfactory profits are specifically expressed as $\pi_{r}^{h}=\left(p_{1}^{d *}-w_{1}^{d *}\right) d_{1}^{c *}+\left(p_{2}^{d *}-w_{2}^{d *}\right) d_{2}^{c *}, \pi_{s 1}^{h}=\left(w_{1}^{d *}-c_{1}\right) d_{1}^{c *}$, and $\pi_{s 2}^{h}=\left(w_{2}^{d *}-c_{2}\right) d_{2}^{c *}$. Being the leader of the supply chain, the retailer will subsidize profits through redistributing value-added profits and let the desired profit interval of supply chain members be $\left[\pi_{i}^{d *}, \pi_{i}^{h}\right]$.

Take the profits under the decentralized decision $\pi_{i}^{d *}$ as the starting point of the bargaining and the profit satisfaction $\pi_{i}^{d *} / \pi_{i}^{h}$ as the starting point of the game negotiation, respectively, and let $\rho$ be the coordinate coefficient of satisfaction of the system. As long as it is greater than the profit satisfaction, the obtained profits through negotiation are agreed by supply chain members. If it is lower than the minimum negotiated profit satisfaction value, the profits obtained through negotiation are unacceptable. According to the above discussion and analysis, by making use of the asymmetric Nash bargaining model, we can establish the following optimization model:

$$
\begin{array}{ll}
\max S= & \left(\frac{\pi_{r}^{n}}{\pi_{r}^{h}}-\frac{\pi_{r}^{d *}}{\pi_{r}^{h}}\right)^{\eta_{r}} \cdot\left(\frac{\pi_{s 1}^{n}}{\pi_{s 1}^{h}}-\frac{\pi_{s 1}^{d *}}{\pi_{s 1}^{h}}\right)^{\eta_{s 1}} \cdot\left(\frac{\pi_{s 2}^{n}}{\pi_{s 2}^{h}}-\frac{\pi_{s 2}^{d *}}{\pi_{s 2}^{h}}\right)^{\eta_{s 2}} \\
\text { s.t. } & \left\{\begin{array}{l}
\pi_{i}^{d *} \leq \pi_{i}^{n} \leq \pi_{r}^{h} \\
\pi_{r}^{n}+\pi_{s 1}^{n}+\pi_{s 2}^{n}<\Delta \pi \\
\pi_{r}^{n}+\pi_{s 1}^{n}+\pi_{s 2}^{n}=\rho \cdot\left(\pi_{r}^{h}+\pi_{s 1}^{h}+\pi_{s 2}^{h}\right) \\
\eta_{r}+\eta_{s 1}+\eta_{s 2}=1 \\
\min \frac{\pi_{i}^{d *}}{\pi_{i}^{h}<\rho<\max \frac{\pi_{i}^{d *}}{\pi_{i}^{h}}} \\
i=r, s 1, s 2 .
\end{array}\right.
\end{array}
$$

Based on the above value-added profit redistribution model, when each supply chain member is willing to realize the redistribution of value-added profits, there may be surplus profits available for distribution. At this time, such profits will be used by the retailer to distribute cooperative profits. At this time, since there is a cooperative alliance in the supply chain, the retailer will subsidize the members, and the profits of continuing the cooperative subsidy are $\Delta \pi \prime=\Delta \pi-\pi_{r}^{n}-\pi_{s 1}^{n}-\pi_{s 2}^{n}$. By using the cooperation effort degrees of supplier 1 to measure its contribution, we can get the differences between the optimal cooperation effort degrees under the decentralized and centralized decision, and contribution degree of supplier 1 to the profit growth of supply chain, respectively, is as follows: $\Delta \pi_{s 1}=\left.\pi^{c *}(s)\right|_{s=s^{c *}}-\left.\pi^{d *}(s)\right|_{s=s^{c *}}, \quad$ and $\quad \theta_{s 1}=\Delta \pi_{s 1} / \pi^{c *}$. Therefore, the profit subsidy of supplier 1 is $\pi_{s 1}^{n^{\prime}}=\theta_{s 1} \cdot \Delta \pi \prime$, and the retailer's final satisfaction profits after the coordination is $\pi_{r}^{n *}=\Delta \pi-\pi_{s 1}^{n *}-\pi_{s 2}^{n *}$. Based on the proposed mechanism, the profits after the coordination under the centralized decision are not lower than those under the decentralized decision, which shows that the proposed coordination mechanism is effective.

\section{Conclusions}

Concerning the coordination problem of the supply chain, we analyze the optimal decisions under the decentralized and centralized decision and explore the impact of cooperation effort degree on the profits of supply chain members and then design a coordination mechanism through valueadded benefit distribution. According to the above discussion and analysis, the proposed coordination mechanism can effectively deal with conflict problem and guarantee supply chain members and supply chain to maximize their profits and adopt the centralized decision. Meanwhile, the profits of the supply chain and supply chain members, 
optimal retail price, and optimal sales volume under the centralized decision are larger than those under the decentralized decision. The profits of the retailer increase with the increase of suppliers' cooperation effort degrees; meanwhile, higher supply chain profits can be obtained after the coordination of group satisfaction.

Although the proposed coordination mechanism has been well verified, there exist some shortcomings. For example, this paper does not consider the coordination problems of the supply chains with multiple products and retailers.

\section{Data Availability}

The data used to support the findings of this study are available from the corresponding author upon request (liuy@jiangnan.edu.cn or clly1985528@163.com).

\section{Conflicts of Interest}

The authors declare that they have no conflicts of interest.

\section{Acknowledgments}

This work was partially funded by the National Natural Science Foundation of China (71503103), the Humanities and Social Sciences of Education Ministry (17YJC640233), Natural Science Foundation of Jiangsu Province (BK20150157), Soft Science Foundation of Jiangsu Province (BR2018005), Jiangsu Province University Philosophy and Social Sciences for Key Research Program (2017ZDIXM034), the Fundamental Research Funds for the Central Universities (2019JDZD06) and Research Project from Jiangsu Association of Science and Technology (JSKXKT 2020023), and the Tender Project from Wuxi Federation of Philosophy and Social Sciences (WXSK20-A08) and Soft Science Foundation of Wuxi City (KX-19-A23).

\section{References}

[1] H. Song and X. Gao, "Green supply chain game model and analysis under revenue-sharing contract," Journal of Cleaner Production, vol. 170, pp. 183-192, 2018.

[2] T. Chakraborty, S. S. Chauhan, and N. Vidyarthi, "Coordination and competition in a common retailer channel: wholesale price versus revenue-sharing mechanisms," International Journal of Production Economics, vol. 166, pp. 103118, 2015.

[3] Y. Gerchak and Y. Wang, "Revenue-sharing vs. wholesaleprice contracts in assembly systems with random demand," Production and Operations Management, vol. 13, no. 1, pp. 23-33, 2004.

[4] W. Antweiler, "A two-part feed-in-tariff for intermittent electricity generation," Energy Economics, vol. 65, pp. 458470, 2017.

[5] D. Basak and L. F. S. Wang, "Endogenous choice of price or quantity contract and the implications of two-part-tariff in a vertical structure," Economics Letters, vol. 138, pp. 53-56, 2016.

[6] Q. Bai, M. Chen, and L. Xu, "Revenue and promotional costsharing contract versus two-part tariff contract in coordinating sustainable supply chain systems with deteriorating items," International Journal of Production Economics, vol. 187, pp. 85-101, 2017.

[7] J. Heydari, K. Govindan, R. Sadeghi et al., "Reverse supply chain coordination under stochastic remanufacturing capacity," International Journal of Production Economics, vol. 202, pp. 1-11, 2018.

[8] S. M. Aljazzar, M. Y. Jaber, and L. Moussawi-Haidar, "Coordination of a three-level supply chain (supplier-manufacturer-retailer) with permissible delay in payments and price discounts," Applied Mathematical Modelling, vol. 48, pp. 289-302, 2017.

[9] J. Heydari, "Supply chain coordination using time-based temporary price discounts," Computers \& Industrial Engineering, vol. 75, pp. 96-101, 2014.

[10] R. W. Seifert, R. I. Zequeira, and S. Liao, "A three-echelon supply chain with price-only contracts and sub-supply chain coordination," International Journal of Production Economics, vol. 138, no. 2, pp. 345-353, 2012.

[11] T. Xiao and X. Qi, "Price competition, cost and demand disruptions and coordination of a supply chain with one manufacturer and two competing retailers," Omega, vol. 36, no. 5, pp. 741-753, 2008.

[12] S. K. Chaharsooghi, J. Heydari, and I. N. Kamalabadi, "Simultaneous coordination of order quantity and reorder point in a two-stage supply chain," Computers \& Operations Research, vol. 38, no. 12, pp. 1667-1677, 2011.

[13] H. L. Lee and M. J. Rosenblatt, "A generalized quantity discount pricing model to increase supplier's profits," Management Science, vol. 32, no. 9, pp. 1177-1185, 1986.

[14] J. P. Monahan, "A quantity discount pricing model to increase vendor profits," Management Science, vol. 30, no. 6, pp. 720-726, 1984.

[15] S. Beil, T. Nishi, and I. E. Grossmann, "Optimal quantity discount coordination for supply chain optimization with one manufacturer and multiple suppliers under demand uncertainty," The International Journal of Advanced Manufacturing Technology, vol. 76, no. 5-8, pp. 1173-1184, 2015.

[16] B. A. Pasternack, "Optimal pricing and return policies for perishable commodities," Marketing Science, vol. 4, no. 2, pp. 166-176, 1985.

[17] J. Heydari, T.-M. Choi, S. Radkhah et al., "Pareto improving supply chain coordination under a money-back guarantee service program," Service Science, vol. 9, no. 2, pp. 91-105, 2017.

[18] J. Hou, A. Z. Zeng, and L. Zhao, "Coordination with a backup supplier through buy-back contract under supply disruption," Transportation Research Part E: Logistics and Transportation Review, vol. 46, no. 6, pp. 881-895, 2010.

[19] Y. Song, S. Ray, and S. Li, "Structural properties of buyback contracts for price-setting newsvendors," Manufacturing \& Service Operations Management, vol. 10, no. 1, pp. 1-18, 2008.

[20] K. Chen and T. Xiao, "Outsourcing strategy and production disruption of supply chain with demand and capacity allocation uncertainties," International Journal of Production Economics, vol. 170, pp. 243-257, 2015.

[21] B. C. Giri and S. Bardhan, "Coordinating a supply chain with backup supplier through buyback contract under supply disruption and uncertain demand," International Journal of Systems Science: Operations \& Logistics, vol. 1, no. 4, pp. 193-204, 2014.

[22] J. Heydari and M. Ghasemi, "A revenue sharing contract for reverse supply chain coordination under stochastic quality of returned products and uncertain remanufacturing capacity," Journal of Cleaner Production, vol. 197, pp. 607-615, 2018. 
[23] J. Heydari, P. Zaabiahmadi, T. Choi et al., "Coordinating supply chains with stochastic demand by crashing lead times," Computers \& Operations Research, vol. 100, pp. 394-403, 2016.

[24] X. Fang, "Analysis of double marginalization effect on the wholesale price contract coordination," Asia-Pacific Journal of Operational Research, vol. 35, no. 2, Article ID 1840005, pp. 1-15, 2018.

[25] X. Wang, X. Wang, and Y. Su, "Wholesale-price contract of supply chain with information gathering," Applied Mathematical Modelling, vol. 37, no. 6, pp. 3848-3860, 2013.

[26] C. F. Lan and H. Y. Ji, "Wholesale price contract under fairness preference with random capacity and random demand," Universidad Central de Venezuela, vol. 31, no. 3, pp. 12-27, 2016.

[27] B. Hu, C. Meng, D. Xu, and Y.-J. Son, "Supply chain coordination under vendor managed inventory-consignment stocking contracts with whole'sale price constraint and fairness," International Journal of Production Economics, vol. 202, pp. 21-31, 2018.

[28] M. San Martín and A. I. Saracho, "Patent strength and optimal two-part tariff licensing with a potential rival incorporating ad valorem royalties," Economics Letters, vol. 143, pp. 28-31, 2016.

[29] P. Forrest, J. Shang, and H. Wang, "Enhancing corporate social responsibility: contract design under information asymmetry," Omega, vol. 67, pp. 19-30, 2017.

[30] J. Heydari, K. Govindan, H. R. Nasab, and A. A. Taleizadeh, "Coordination by quantity flexibility contract in a two-echelon supply chain system: effect of outsourcing decisions," International Journal of Production Economics, vol. 225, Article ID 107586, 2019.

[31] Z. Yang, G. Aydın, V. Babich, and D. R. Beil, "Supply disruptions, asymmetric information, and a backup production option," Management Science, vol. 55, no. 2, pp. 192-209, 2009.

[32] G. P. Cachon, "Supply chain coordination with contracts," in Handbooks in Operations Research and Management Science, vol. 11, pp. 227-339, Spriger, Berlin, Germany, 2003.

[33] J. Gaudreault, J.-M. Frayret, and G. Pesant, "Distributed search for supply chain coordination," Computers in Industry, vol. 60, no. 6, pp. 441-451, 2009.

[34] Z. Huang, S. X. Li, and V. Mahajan, "An analysis of manufacturer-retailer supply chain coordination in cooperative advertising," Decision Sciences, vol. 33, no. 3, pp. 469-494, 2002.

[35] S. P. Sethi, H. Yan, and H. Zhang, "Quantity flexibility contracts: optimal decisions with information updates," Decision Sciences, vol. 35, no. 4, pp. 691-712, 2004.

[36] X. Yue and S. Raghunathan, "The impacts of the full returns policy on a supply chain with information asymmetry," European Journal of Operational Research, vol. 180, no. 2, pp. 630-647, 2007.

[37] J. Heydari and Y. Norouzinasab, “A two-level discount model for coordinating a decentralized supply chain considering stochastic price-sensitive demand," Journal of Industrial Engineering International, vol. 11, no. 4, pp. 531-542, 2015.

[38] H. Huang, H. Ke, and L. Wang, "Equilibrium analysis of pricing competition and cooperation in supply chain with one common manufacturer and duopoly retailers," International Journal of Production Economics, vol. 178, pp. 12-21, 2016.

[39] C. Marinagi, P. Trivellas, and P. Reklitis, "Information quality and supply chain performance: the mediating role of information sharing," Procedia-Social and Behavioral Sciences, vol. 175, pp. 473-479, 2015.

[40] J. Chaeb and M. Rasti-Barzoki, "Coordination via cooperative advertising and pricing in a manufacturer-retailer supply chain," Computer and Industrial Engineering, vol. 99, pp. 112-123, 2017.

[41] T.-H. Chen, "On the impact of cooperative advertising and pricing for a manufacturer-retailer supply chain," Journal of Industrial and Production Engineering, vol. 31, no. 7, pp. 417-424, 2014.

[42] C.-T. Zhang, H.-X. Wang, and M.-L. Ren, "Research on pricing and coordination strategy of green supply chain under hybrid production mode," Computers \& Industrial Engineering, vol. 72, pp. 24-31, 2014.

[43] S. Du, L. Hu, and L. Wang, "Low-carbon supply policies and supply chain performance with carbon concerned demand," Annals of Operations Research, vol. 255, no. 1-2, pp. 569-590, 2017.

[44] L. Xu, Y. Li, K. Govindan, and X. Xu, "Consumer returns policies with endogenous deadline and supply chain coordination," European Journal of Operational Research, vol. 242, no. 1, pp. 88-99, 2015.

[45] Y. Liu, B.-T. Quan, Q. Xu, and J. Y.-L. Forrest, "Corporate social responsibility and decision analysis in a supply chain through government subsidy," Journal of Cleaner Production, vol. 208, pp. 436-447, 2019.

[46] M. Sinayi and M. Rasti-Barzoki, "A game theoretic approach for pricing, greening, and social welfare policies in a supply chain with government intervention," Journal of Cleaner Production, vol. 196, pp. 1443-1458, 2018.

[47] Y. H. Zhang and Y. Wang, "The impact of government incentive on the two competing supply chains under the perspective of corporation social responsibility: a case study of photovoltaic industry," Journal of Cleaner Production, vol. 154, pp. 102-113, 2017.

[48] A. Arya and B. Mittendorf, "Supply chain consequences of subsidies for corporate social responsibility," Production and Operations Management, vol. 24, no. 8, pp. 1346-1357, 2015.

[49] A. Hafezalkotob, "Competition of two green and regular supply chains under environmental protection and revenue seeking policies of government," Computers \& Industrial Engineering, vol. 82, pp. 103-114, 2015.

[50] S. S. Chauhan and J.-M. Proth, "Analysis of a supply chain partnership with revenue sharing," International Journal of Production Economics, vol. 97, no. 1, pp. 44-51, 2005.

[51] H. V. Arani, M. Rabbani, and H. Rafiei, "A revenue-sharing option contract toward coordination of supply chains," International Journal of Production Economics, vol. 178, pp. 42-56, 2016.

[52] J. Heydari and Z. Mosanna, "Coordination of a sustainable supply chain contributing in a cause-related marketing campaign," Journal of Cleaner Production, vol. 200, pp. 524532, 2018.

[53] D. Ghosh and J. Shah, "Supply chain analysis under green sensitive consumer demand and cost sharing contract," International Journal of Production Economics, vol. 164, pp. 319-329, 2015.

[54] S. Panda, "Coordination of a socially responsible supply chain using revenue sharing contract," Transportation Research Part E: Logistics and Transportation Review, vol. 67, pp. 92-104, 2014.

[55] S. Panda and N. M. Modak, "Exploring the effects of social responsibility on coordination and profit division in a supply chain," Journal of Cleaner Production, vol. 139, pp. 5-40, 2016. 
[56] S. Panda, N. M. Modak, and L. E. Cárdenas-Barrón, "Coordinating a socially responsible closed-loop supply chain with product recycling," International Journal of Production Economics, vol. 188, pp. 11-21, 2017.

[57] S. Panda, N. M. Modak, M. Basu, and S. K. Goyal, "Channel coordination and profit distribution in a social responsible three-layer supply chain," International Journal of Production Economics, vol. 168, pp. 224-233, 2015.

[58] S. Goyal, N. M. Modak, and D. Pradhan, "Corporate social responsibility, channel coordination and profit division in a two-echelon supply chain," International Journal of Management Science and Engineering Management, vol. 11, no. 1, pp. 22-33, 2016.

[59] R. C. Savaskan, S. Bhattacharya, and L. N. Van Wassenhove, "Closed-loop supply chain models with product remanufacturing," Management Science, vol. 50, no. 2, pp. 239-252, 2004.

[60] S. R. Bhaskaran and V. Krishnan, "Effort, revenue, and cost sharing mechanisms for collaborative new product development," Management Science, vol. 55, no. 7, pp. 1152-1169, 2009.

[61] J. Zhao and J. Wei, "The coordinating contracts for a fuzzy supply chain with effort and price dependent demand," Applied Mathematical Modelling, vol. 38, no. 9-10, pp. 2476-2489, 2014. 